\title{
38 School-based empathy policy
}

\author{
A holistic approach \\ Aileen Fullchange, Méroudjie Denis, and \\ Leann V. Smith
}

\section{How to use this policy}

Empathy is a far-reaching skill with deep evolutionary roots that has allowed us to survive and thrive (De Waal, 2008). Those with more empathy tend to have better life outcomes. Of particular significance during this time in history when racial tensions are becoming more publicized and social issues related to public health and universal humanity are at the forefront of policy issues, empathy may play a more important role. In fact, empathy can help reduce prejudice and bias, perhaps contributing to dismantling centuries-old racist systems in our societies, and in helping us to evolve into a more just and meaningfully connected society.

This policy example is intentionally broad and school policy creators are encouraged to delete and build upon suggestions below to create a policy that best represents their school. Additionally, implementing a policy successfully requires involvement of all relevant stakeholders and individuals who might be impacted by the policy. Hence, this policy should be reviewed not just by school leadership but also by students and their caregivers, teachers, and school support staff, such as mental health personnel, front office staff, and all others who might be affected by such a policy. Empathy is a skill developed by experiencing it; hence, a policy that aims to cultivate empathy should be developed via processes that allow for demonstration of empathy and inclusion.

[To adapt and use this policy delete or modify the text as indicated]

\section{[INSERT name of school] School-based empathy policy: A holistic approach}

\section{Rationale}

In this policy empathy is defined as "the ability to understand and share in another's emotional state or context" (Cohen \& Strayer, 1996, p. 988). Empathy is perhaps the single most important contributor to social functioning and is highly correlated with positive mental health outcomes (Riess, 
2017) and higher levels of self-esteem (Laible et al., 2004). Empathy is also correlated with prosocial behaviors across the lifespan (Knafo et al., 2008; Masten et al., 2011; Trommsdorff et al., 2007; Van der Graaff et al., 2018; Yoo et al., 2013) and supports academic outcomes and resiliency (Leontopoulou, 2010; Zorza et al., 2013). Most noteworthy during this era, empathy is perhaps even more vital now, as hate crimes have risen in some countries (Edwards \& Rushin, 2018), with the largest portion of such incidents in schools (Southern Poverty Law Center, 2017). Empathy training can result in reduced implicit biases (Herrera et al., 2018). Youth who exhibit higher empathy levels, especially perspective taking, tend to be less prejudiced (Miklikowska, 2018), and interventions that specifically target empathy seem to be effective at reducing prejudice (Beelmann \& Heinemann, 2014). Furthermore, evidence suggests that deficits in empathy have detrimental consequences, including psychopathology, bullying perpetration (Jolliffe \& Farrington, 2006), aggression (Lovett \& Sheffield, 2007), anger (Day et al., 2012), and being a victim of bullying (Wood et al., 2009).

Empathy training is not needed solely for students. It is crucial for school staff too. One study showed that empathy training for teachers resulted in reduced biases, especially toward minority students (Whitford \& Emerson, 2019). This has implications for addressing implicit bias and racial biases in schools, which perhaps contribute to some of the disproportionate representation of children of color in disciplinary referrals and special education (Losen et al., 2014) and the phenomenon of the school-to-prison pipeline (Togut, 2011). Such findings give hope to the possibility of combatting the current wave of anti-immigrant and xenophobic sentiments, dismantling longentrenched systems biased against youth of color, and addressing racial trauma.

\section{Purpose}

The purpose of this policy is to enable - leadership, staff, and students - to co-create environments that maximize the possibility of healthy empathy development in youth. Guiding principles as well as specific structures and strategies are provided.

\section{Scope}

This policy applies to school leadership, teaching staff, and students of [INSERT name of school].

[INSERT specific roles and responsibilities of individuals or teams]

\section{Policy statement}

Any policy that aims to develop the empathy of students must be rooted in research findings indicating that children develop empathy from receiving 


\section{2}

empathy themselves (Teymoori \& Shahrazad, 2012). Hence, the foundation of this policy is in primarily ensuring that the school-based caregivers (e.g., teachers, school staff, school leaders, etc.) in a child's life are equipped with intact empathy. This foundation will be termed Tier 0. Additionally, we acknowledge that effective school-based policies must be comprehensive and, hence, a multi-tiered system of support (MTSS) that addresses the three tiers of intervention must be utilized; these will be termed Tiers 1, 2, and 3 . Finally, we acknowledge that empathy-promoting policies must both prevent those factors that decrease empathy from occurring as well as intervene when there is already a lack of empathy. Hence, both prevention and intervention strategies must be part of this policy.

\section{Tier 0 support: School-based caregivers as the foundation}

We at [INSERT name of school] must provide school-based caregivers, including but not limited to teachers, counselors, front office staff, cafeteria workers, and all other personnel who provide care for children, with ways to assess for their own empathic capacities and to assess distress, a barrier to empathy (Hoffman, 2000), using research-validated measures (e.g., Interpersonal Reactivity Index; Davis, 1994). Additionally, school leadership will provide school-based caregivers with dedicated space and time to individually and collectively self-assess empathy and distress levels. Other forms of schoolbased self-assessment for empathy will be utilized including, but not limited to, assessing patterns and trends of negative interactions with students as evidenced by office referrals, disciplinary actions, and student/parent-report as well as patterns of teaching styles that lead to suboptimal relationship building between students and teachers.

We at [INSERT name of school] will create an environment that aims to prevent school-based caregivers' distress. The rates of trauma in students continues to increase and research shows that over half of individuals who work with traumatized youth will display symptoms of compassion fatigue, which can lead to unintended negative emotional states, such as burnout, depression, and anxiety. Thus, school leadership supports the following research-based strategies:

- Regularly assess for staff's internal factors that contribute to burnout, such as workload, years of experience, and social support (AbrahamCook, 2012), and assess for external factors, including ambiguous role expectations, excessive time demands, classes that are too large, poor staff culture, inadequate facilities, resources, or supplies, and salaries that are inadequate (Haberman, 2005).

- Encourage work/life balance.

- Introduce school-based caregivers to self-management and stressmanagement skills (Bartlett et al., 2019). 
- Increase school staff's social support and sense of connectedness (Halbesleben, 2006).

- Increase teacher and staff motivation by increasing teacher and staff support (Betoret, 2006).

- Promote a democratic school environment that promotes school-based caregivers' decision-making abilities, autonomy, and direct input on policies and procedures that directly affect them (Dworkin et al., 2003).

We at [INSERT name of school] will provide frontline staff who report experiencing distress or who demonstrate difficulties with empathic skills with:

- Easy access to mental health support services (Whitaker et al., 2009), such as individual counseling and group support services that are confidential.

- Individualized training and support to increase staff's ability to connect with students (Haberman, 2005) in areas such as cultural competence, racial identity development awareness, and trauma-informed care.

We at [INSERT name of school] will provide school-based caregivers with knowledge and skills to demonstrate empathy toward students, including:

- Scientifically-based information about empathy development (e.g. Fullchange, 2016a; 2016b; Fullchange, in press).

- Individual coaching to support teachers in developing a self-reflective teaching practice.

- Opportunities for school-based caregivers to take on the perspective of students, such as following a student for a day (Strauss, 2014) or visiting students' communities and home contexts (Peck et al., 2015), to promote more pluralistic attitudes towards student diversity (Smith et al., 2020).

\section{Tier I: All students}

We at [INSERT name of school] will provide whole-school approaches to fostering empathy. At the foundation of this tier is data gathering in the form of universal social-emotional screening. It is especially important to assess for complex trauma, as this often correlates with difficulties in expressing empathy (Pears \& Fisher, 2005).

Because the research has demonstrated that children develop empathy from receiving empathy themselves, the school environment must promote their experiences of empathy and, thus, must be safe and stable, and have clear expectations, and supports to meet those expectations. Hence, the following school-wide practices will be established: 


\section{Fullchange, Denis \& Smith}

- Clearly communicated behavioral, academic, and social-emotional student and staff expectations that are collaboratively and equitably developed and reviewed with students and families throughout the academic year and are communicated in multiple modalities, such as verbally and visually (Bradshaw et al., 2012).

- Eliminate racially disproportionately exclusionary policies, like office referrals, suspensions, expulsions, etc. that create ruptures in relationships and hinder empathy and use alternatives, such as Restorative Justice practices, Positive Behavior Interventions and Supports, and peer mediation.

- Cultivate school connectedness, using a variety of strategies to include students and their families (see Centers for Disease Control, 2009, p. 15 for further reading).

The following universal interventions for students will also be implemented by school-based caregivers at [INSERT name of school]. These interventions will be implemented within the context of school-based caregivers' empathic relationships with students:

- When others appear distressed, acknowledge the distress, help students see their own contributions to others' distress (Hoffman, 2000), and/or question and expand their viewpoints about others' perspectives (Peterson \& Skevington, 1988).

- Incorporate role playing via acting classes into existing curricula (Goldstein \& Winner, 2012) (e.g., have students role-play various historical figures in a social study class).

- Incorporate regular gratitude (McCullough et al., 2002) and mindfulness practices (Mascaro et al., 2013).

- Create opportunities for students from differing backgrounds to participate in group activities together, such as creating music (Rabinowitch et al., 2012), and create opportunities for students to engage in cooperative learning structures that promote interdependence, such as jigsaws (Aronson, 2002).

- Provide regular verbal and visual reminders of safety (Mikulincer \& Shaver, 2005) - both safe people (e.g., pictures of safe caregivers) and safe situations (e.g., stories in which a fictional character experiences safety).

- Consider structured social-emotional learning (SEL) programs that include empathy as a targeted component, such as Incredible Years School Dinosaur Program (Webster-Stratton et al., 2008), PATHS (Conduct Problems Prevention Research Group, 2010), RULER (Brackett et al., 2012), Second Step (Holsen et al., 2008). Consider SEL programs that target empathy specifically, such as Roots of Empathy (Schonert-Reichl et al., 2012) and HEROES (Fullchange, 2017). 


\section{Tier II: Small groups}

For students who do not respond to Tier I interventions, [INSERT name of school] will consider increasing the depth and/or frequency of the aforementioned interventions, especially focusing on students having opportunities to develop safe relationships with adult caregivers and peers in small groups. Examples of such interventions might include small group pullouts for targeted support using any of the above strategies or programs. The HEROES program in particular is designed for small group intervention (Fullchange, 2017).

\section{Tier III: Individual interventions}

At this level of intervention, [INSERT name of school] will consider individualized services, such as supporting students' experiences of empathy in the context of a one-on-one relationship with a safe school-based caregiver, as is done in a check-in/check-out system (Swoszowski, 2014) with an individual counselor or mental health provider.

\section{Authorship}

Aileen Fullchange, $\mathrm{PhD}$, Momentous Institute

Méroudjie Denis, PhD, Momentous Institute

Leann V. Smith, PhD, Texas A\&M University

[INSERT RELEVANT STAFF MEMBERS]

\section{Date of ratification}

This policy was ratified on the [INSERT DATE].

\section{Date of review}

This policy will be reviewed by [INSERT DATE].

\section{Expert consultation}

It is recommended that schools work closely with their mental health team, such as school counselors and school psychologists, in order to implement Tier II and III interventions. School mental health staff should also be contacted to provide trauma-informed care training to all school staff. Schools should also work closely with their local community mental health agencies to help connect students and caregivers in the school (teachers, administrators, etc.) to mental health services. 


\section{Rating of evidence base}

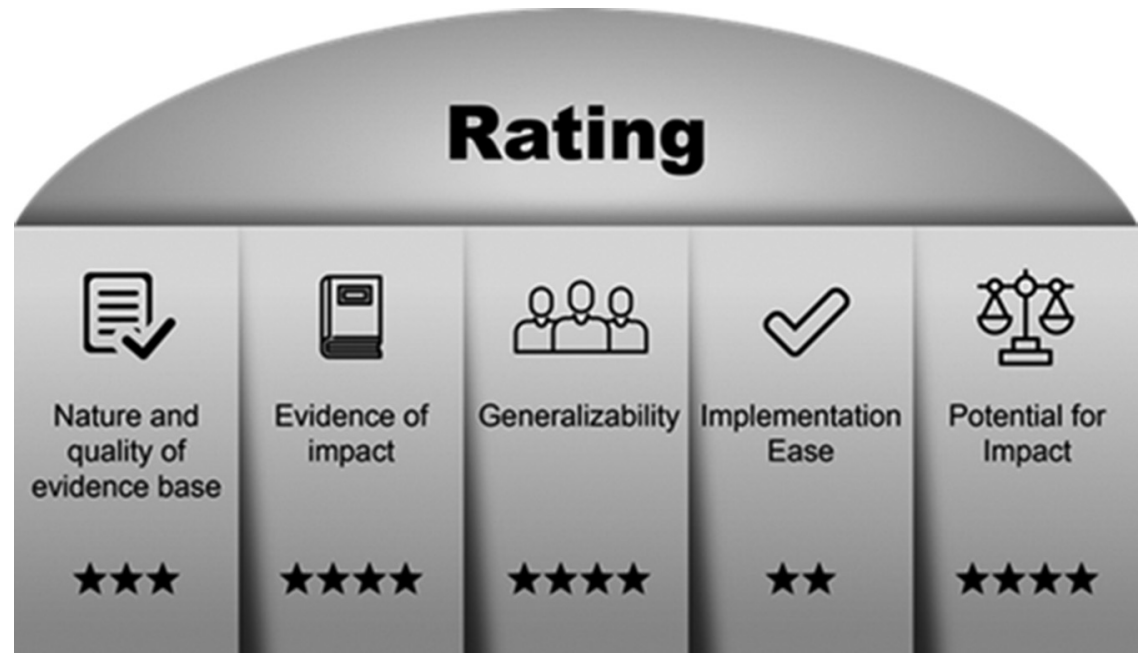

Figure 38.1. School-Based Empathy Rating of Evidence.

Author Note. Empathy is a well-researched area with large support for positive impacts on social-emotional development of all children. Nonetheless, there continues to be a need for more research in school-based settings with diverse populations. Further, empathy policies have not yet been well-established in schools for researchers to examine. Hopefully, the nature/quality of the evidence base will improve over time as more studies are done. Nonetheless, empathy is perhaps the single most important contributor to social-emotional functioning. There are a myriad of studies linking empathy with positive outcomes such as prosocial behaviors, academic success, social relationships, wellbeing, resilience, moral development, and reduced racial bias. There are also many studies showing that lack of empathy can lead to negative outcomes. These policies are highly generalizable, as is a universal human experience and a construct that has arguably been vital in the existence of humans as social, interconnected, and interdependent beings. yet, schools often fail to explicitly teach students these important skills. While this policy can be embedded into daily, common practices of a school, to fully and effectively implement it, staff should receive training and coaching in trauma-informed care, racial bias, and cultural awareness. Implementing this policy will require schools to partner with local community mental health agencies and to work closely with school counselors, school psychologists and social workers to ensure students receive appropriate interventions across all tiers of support. Despite the potentially complex nature of implementing this policy, there is excellent potential for positive impact. Building empathy builds positive classroom and school culture and strengthens communities. This policy will ensure that schools are intentionally creating safer and social-emotionally healthier environments for all students and staff. Given the heightened awareness of race relations in many countries, the momentum for dismantling racist systems, and the role that empathy plays in reducing prejudices, this policy may come at an especially crucial time for many schools. 


\section{References}

Abraham-Cook, S. (2012). The prevalence and correlates of compassion fatigue, compassion satisfaction, and burnout among teachers working in high-poverty urban public schools [Doctoral dissertation, Seton Hall University]. https://scholarship.shu. edu/cgi/viewcontent.cgi?article $=2820 \&$ context $=$ dissertations

Aronson, E. (2002). Building empathy, compassion, and achievement in the Jigsaw Classroom. Improving Academic Achievement, 209-225.

Bartlett, L., Martin, A., Neil, A. L., Memish, K., Otahal, P., Kilpatrick, M., \& Sanderson, K. (2019). A systematic review and meta-analysis of workplace mindfulness training randomized controlled trials. Journal of Occupational Health Psychology, 24(1), 108-126.

Beelmann, A., \& Heinemann, K. S. (2014). Preventing prejudice and improving intergroup attitudes: A meta-analysis of child and adolescent training programs. Journal of Applied Developmental Psychology, 35(1), 10-24.

Betoret, F. D. (2006). Stressors, self-efficacy, coping resources, and burnout among secondary school teachers in Spain. Educational Psychology, 26(4), 519-539.

Brackett, M. A., Rivers, S. E., Reyes, M. R., \& Salovey, P. (2012). Enhancing academic performance and social and emotional competence with the RULER feeling words curriculum. Learning and Individual Differences, 22(2), 218-224.

Bradshaw, C. P., Waasdorp, T. E., \& Leaf, P. J. (2012). Effects of school-wide positive behavioral interventions and supports on child behavior problems. Pediatrics, 130(5), e1136-e1145.

Centers for Disease Control and Prevention. (2009). School connectedness: Strategies for increasing protective factors among youth. Atlanta, GA: US Department of Health and Human Services.

Cohen, D., \& Strayer, J. (1996). Empathy in conduct-disordered and comparison youth. Developmental Psychology, 32, 988-998.

Conduct Problems Prevention Research Group. (2010). Fast Track intervention effects on youth arrests and delinquency. Journal of Experimental Criminology, 6(2), 131-157.

Davis, M. H. (1994). Empathy: A social psychological approach. Wisconsin: Brown \& Benchmark.

Day, A., Mohr, P., Howells, K., Gerace, A., \& Lim, L. (2012). The role of empathy in anger arousal in violent offenders and university students. International Journal of Offender Therapy and Comparative Criminology, 56(4), 599-613.

De Waal, F. B. M. (2008). Putting the altruism back into altruism: The evolution of empathy. Annual Review of Psychology, 59(1), 279-300.

Dworkin, A. G., Saha, L. J., \& Hill, A. N. (2003). Teacher burnout and perceptions of a democratic school environment. International Education Journal, 4(2), 108-120.

Edwards, G. S., \& Rushin, S. (2018, January 18). The effect of President Trump's election on hate crimes. SSRN. https://papers.ssrn.com/sol3/papers.cfm?abstract_id= 3102652

Fullchange, A. (2016a). Activities to increase cognitive empathy in students. NASP Communique, 45(1). https://www.nasponline.org/publications/periodicals/communique/ issues/volume-45-issue-2/activities-to-increase-cognitive-empathy-in-students

Fullchange, A. (2016b). Empathy and potential for positive outcomes for at-risk youth. NASP Communique, 45(2). https://www.nasponline.org/publications/periodicals/ communique/issues/volume-45-issue-1 
Fullchange, A. (2017). Effectiveness of an empathy intervention for youths at-risk [Unpublished doctoral dissertation]. University of California Santa Barbara.

Fullchange, A. (in press). Empathy, prosocial behavior, and positive development in schools. In K. Allen, M. Furlong, D. Vella-Brodrick, \& S. Suldo (Eds.) Handbook of positive psychology in schools: In support of positive educational processes (3rd ed). New York, NY: Routledge Taylor \& Francis.

Goldstein, T. R., \& Winner, E. (2012). Enhancing empathy and theory of mind. Journal of Cognition and Development, 13(1), 19-37.

Haberman, M. (2005). Teacher burnout in black and white. The New Educator, 1(3), $153-175$.

Halbesleben, J. R. B. (2006). Sources of social support and burnout: A meta-analytic test of the conservation of resources model. Journal of Applied Psychology, 91(5), $1134-1145$.

Herrera, F., Bailenson, J., Weisz, E., Ogle, E., \& Zaki, J. (2018). Building long-term empathy: A large-scale comparison of traditional and virtual reality perspectivetaking. PloS one, 13(10), e0204494.

Hoffman, M. L. (2000). Empathy and moral development: Implications for caring and justice. Cambridge: Cambridge University Press.

Holsen, I., Smith, B. H., \& Frey, K. S. (2008). Outcomes of the social competence program Second Step in Norwegian elementary schools. School Psychology International, 29(1), 71-88.

Jolliffe, D., \& Farrington, D. P. (2006). Examining the relationship between low empathy and bullying. Aggressive Behavior, 32(6), 540-550.

Knafo, A., Zahn-Waxler, C., Van Hulle, C., Robinson, J. L., \& Rhee, S. H. (2008). The developmental origins of a disposition toward empathy: genetic and environmental contributions. Emotion, 8(6), 737-752.

Laible, D. J., Carlo, G., \& Roesch, S. C. (2004). Pathways to self-esteem in late adolescence: The role of parent and peer attachment, empathy, and social behaviours. Journal of Adolescence, 27, 703-716.

Leontopoulou, S. (2010). An exploratory study of altruism in Greek children: Relations with empathy, resilience and classroom climate. Psychology, 1(5), 377-385.

Losen, D., Hodson, C., Ee, J., \& Martinez, T. (2014). Disturbing inequities: Exploring the relationship between racial disparities in special education identification and discipline. Journal of Applied Research on Children, 5(2), Article 15.

Lovett, B. J., \& Sheffield, R. A. (2007). Affective empathy deficits in aggressive children and adolescents: A critical review. Clinical Psychology Review, 27, 1-13.

Mascaro, J. S., Rilling, J. K., Negi, L. T., \& Raison, C. L. (2013). Compassion meditation enhances empathic accuracy and related neural activity. Social Cognitive and Affective Neuroscience, 8(1), 48-55.

Masten, C. L., Morelli, S. A., \& Eisenberger, N. I. (2011). An fMRI investigation of empathy for 'social pain' and subsequent prosocial behavior. Neuroimage, 55(1), 381-388.

McCullough, M. E., Emmons, R. A., \& Tsang, J.-A. (2002). The grateful disposition: A conceptual and empirical topography. Journal of Personality and Social Psychology, 82(1), 112-127.

Miklikowska, M. (2018). Empathy trumps prejudice: The longitudinal relation between empathy and anti-immigrant attitudes in adolescence. Developmental Psychology, 54(4), 703-717. 
Mikulincer, M., \& Shaver, P. R. (2005). Attachment security, compassion, and altruism. Current Directions in Psychological Science, 14(1), 34-38.

Pears, K. C., \& Fisher, P. A. (2005). Emotion understanding and theory of mind among maltreated children in foster care: Evidence of deficits. Development and Psychopathology, 17(1), 47-65.

Peck, N. F., Maude, S. P., \& Brotherson, M. J. (2015). Understanding preschool teachers' perspectives on empathy: A qualitative inquiry. Early Childhood Education Journal, 43(3), 169-179.

Peterson, C., \& Skevington, S. (1988). The relation between young children's cognitive role-taking and mothers' preference for a conflict-inducing childrearing method. The Journal of Genetic Psychology: Research and Theory on Human Development, 149, 163-174.

Rabinowitch, T., Cross, I., \& Burnard, P. (2012). Musical group interaction, intersubjectivity and merged subjectivity. In D. Reynolds, \& M. Reason (Eds.), Kinesthetic empathy in creative and cultural practices (pp. 109-120). Bristol: Intellect Press.

Riess, H. (2017). The science of empathy. Journal of Patient Experience, 4(2), 74-77.

Schonert-Reichl, K. A., Smith, V., Zaidman-Zait, A., \& Hertzman, C. (2012). Promoting children's prosocial behaviors in school: Impact of the "Roots of Empathy" program on the social and emotional competence of school-aged children. School Mental Health: A Multidisciplinary Research and Practice Journal, 4(1), 1-21.

Smith, L.V., Wang, M.-T. \& Hill, D. (2020). Black youths' perceptions of school cultural pluralism, school climate and the mediating role of racial identity. Journal of School Psychology. 83, 50-65.

Southern Poverty Law Center. (2017). The Trump effect. Southern Poverty Law Center. https://www.splcenter.org/fighting-hate/intelligence-report/2017/trump-effect

Strauss, V. (2014, October 24). Teacher spends two days as a student and is shocked at what she learns. The Washington Post. https://www.washingtonpost.com/news/ answer-sheet/wp/2014/10/24/teacher-spends-two-days-as-a-student-and-is-shocked-atwhat-she-learned/

Swoszowski, N. C. (2014). Adapting a tier 2 behavioral intervention, check-in/checkout, to meet students' needs. Intervention in School and Clinic, 49(4), 211-218.

Teymoori, A., \& Shahrazad, W. (2012). Relationship between mother, father, and peer attachment and empathy with moral authority. Ethics \& Behavior, 22(1), 16-29.

Togut, T. D. (2011). The gestalt of the school-to-prison pipeline: The duality of overrepresentation of minorities in special education and racial disparity in school discipline on minorities. Journal of Gender, Social Policy \& the Law, 20(1), 163-181.

Trommsdorff, G., Friedlmeier, W., \& Mayer, B. (2007). Sympathy, distress, and prosocial behavior of preschool children in four cultures. International Journal of Behavioral Development, 31(3), 284-293.

Van der Graaff, J., Carlo, G., Crocetti, E., Koot, H. M., \& Branje, S. (2018). Prosocial behavior in adolescence: Gender differences in development and links with empathy. Journal of Youth and Adolescence, 47(5), 1086-1099.

Vaughn, S. R., Ridley, C. A., \& Bullock, D. D. (1984). Interpersonal problem-solving skills training with aggressive young children. Journal of Applied Developmental Psychology, 5(3), 213-223.

Webster-Stratton, C., Jamila Reid, M., \& Stoolmiller, M. (2008). Preventing conduct problems and improving school readiness: evaluation of the incredible years teacher 
and child training programs in high-risk schools. Journal of Child Psychology and Psychiatry, 49(5), 471-488.

Whitaker, T., Whitaker, B., \& Lumpa, D. (2009). Motivating \& inspiring teachers: The educational leader's guide for building staff morale (2nd ed). Larchmont, NY: Eye On Education Inc.

Whitford, D. K., \& Emerson, A. M. (2019). Empathy intervention to reduce implicit bias in pre-service teachers. Psychological Reports, 122(2), 670-688.

Woods, S., Wolke, D., Nowicki, S., \& Hall, L. (2009). Emotion recognition abilities and empathy of victims of bullying. Child Abuse \& Neglect, 33(5), 307-311.

Yoo, H., Feng, X., \& Day, R. D. (2013). Adolescents' empathy and prosocial behavior in the family context: A longitudinal study. Journal of Youth and Adolescence, 42(12), 1858-1872.

Zorza, J. P., Marino, J., Lemus, S. D., \& Mesas, A. A. (2013). Academic performance and social competence of adolescents: Predictions based on effortful control and empathy. The Spanish Journal of Psychology, 16(e87), 1-12. 